\title{
Teatro e prisão: dentro da cena e da cadeia
}

\author{
Vicente Concilio
}

incursão de práticas teatrais em presídios tem início, como atividade aprovada pelas unidades penais, em meados dos anos 70 , período em que organizações difusoras de políticas de direitos humanos e denunciadoras das torturas e abusos do governo militar geraram um leve abrandamento da rigidez modelar das propostas de encarceramento.

Esse movimento introduziu, ainda que de forma irregular e pouco integrada, algumas propostas diferenciadas no trato com a população carcerária. Surgem então iniciativas que atribuem à arte teatral relevância social e artística, defendendo sua presença em prisões como instrumento capaz de proporcionar a homens e mulheres presos uma experiência estética propiciadora de uma tomada de consciência oriunda da convivência grupal e do desafio de criação de um espetáculo.

Em São Paulo, experiências narradas por Frei Betto (Freire \& Betto, 1986), Maria Rita Freire Costa (Costa, 1983) e Ruth Escobar (Escobar, 1982; Fernandes, 1985) são exemplos da variedade e da vitalidade das práticas cênicas construídas no interior de instituições punitivas, em um momento extremamente delicado da política nacional, em que coexistiam a censura e a "abertura" política, e a luta pelos direi- tos humanos iniciava sua campanha pela repatriação dos exilados ao mesmo tempo em que questionava os valores e práticas dos órgãos de defesa pública, denunciando torturas e trazendo à tona discussão relativa aos desaparecidos políticos.

Essas práticas teatrais, dotadas das particularidades de cada contexto em que estavam inseridas (tipo de presídio, grau de apoio oferecido pela direção da instituição etc.), possuíam em comum o anseio de trazer para a sociedade, com a mediação de um espetáculo teatral, temas importantes do universo carcerário a fim de que se buscassem alternativas para aquelas vidas todas inutilizadas pelo fracasso da prisão em oferecer alternativas ao mundo do crime.

De forma trágica, e a despeito da repercussão que esses projetos atingiram, eles nunca concluíram seu ciclo, expulsos que eram das unidades penais, na medida em que sua visibilidade trazia à tona a incompetência da prisão em realizar seu objetivo declarado, que é o de "ressocializar" indivíduos através do encarceramento.

Ruth Escobar precisou responder processo criminal, acusada de incitar os presos, através do teatro, a uma rebelião que irrompeu no dia de Natal de 1980, na Penitenciária do Estado, causada por uma briga durante o jogo de

Vicente Concilio é ator. 
futebol. E o Projeto "A Arte como Processo de Recriação em Presídios", coordenado por Maria Rita Freire Costa, responsável pela criação de cinco espetáculos teatrais com detentas da Penitenciária Feminina da Capital, é interrompido em 1983, acusado de propiciar a fuga de duas integrantes, que conseguiram escapar da escolta policial durante o transporte das detentas a um espaço de apresentação externo ao presídio.

A despeito do reconhecido valor artístico e da repercussão favorável que ambas experiências atingiram em diversos setores da imprensa e da crítica teatral, o corpo funcional dos presídios preferia associar teatro à subversão, ao desrespeito e à vadiagem. E por aproximadamente quinze anos, a arte teatral ficava restrita a iniciativas dos próprios presos em datas comemorativas ou a iniciativas ligadas às escolas das unidades prisionais, sem contar com um efetivo apoio de programa cultural para a população carcerária.

Esse panorama é alterado quando o TIPP Center $^{1}$ e a FUNAP 2 implantam o Projeto Drama em diversas unidades prisionais de todo o Estado de São Paulo. Este projeto começou em 1995, no Presídio Ataliba Nogueira, em Campinas, como projeto-piloto, e atingiu 34 unidades prisionais até seu encerramento, em dezembro de 2001. Sua metodologia utilizava técnicas consolidadas pelo Centro de Teatro do Oprimido, com o objetivo de propiciar à população prisional um aprendizado relativo à prevenção de doenças sexualmente transmissíveis e, mais tarde, também sobre Direitos Humanos.

Foi um projeto de grande repercussão, que envolvia personalidades de destaque como o próprio Augusto Boal e o diretor teatral in- glês e, na época, professor da Universidade de Manchester, Paul Heritage, além de diversas entidades e órgãos públicos nacionais e internacionais como a Unicamp - Universidade Estadual de Campinas, o Ministério da Saúde e a Secretaria da Administração Penitenciária.

Esse projeto possibilitou a abertura das unidades a outras experiências no campo da arte teatral, e é dentro desse panorama que o então monitor de unidade escolar e diretor teatral Jorge Spínola dá início, em 1998, a um processo de ensaios que tem como objetivo a encenação de O Auto da Compadecida, de Ariano Suassuna, dentro do COC - Centro de Observação Criminológica, ala de segurança máxima do então existente complexo do Carandiru, onde ficavam detidos presos "jurados de morte", caso estivessem em contato com a massa carcerária: estupradores, policiais corruptos e justiceiros. Por essa razão, o COC era considerada uma das unidades mais rígidas de todo o sistema carcerário paulistano, e a presença do teatro custou a obter apoio da direção da casa.

Mas uma vez conquistado o direito de realizar o processo de encenação, mediante uma apresentação prévia ao então diretor da casa, as conquistas do grupo de teatro excederam as melhores previsões iniciais. $\mathrm{O}$ espetáculo não só foi apresentado dentro da unidade como obteve também o direito de ser representado em outros presídios, abrindo um precedente que possibilitou uma série de apresentações públicas de $O$ Auto da Compadecida, durante o ano de 1999, em espaços como o Teatro Sérgio Cardoso e o Tuca.

Sobre a montagem Suassuna escreveu, em sua coluna no jornal Folha de S. Paulo:

1 Theater in Prison and Probation, centro ligado à Universidade de Manchester, na Inglaterra, com o objetivo de pesquisar a utilização de técnicas dramáticas em programas envolvendo população presa ou em liberdade condicional.

2 A FUNAP - Fundação Professor Manuel Pedro Pimentel de Amparo ao Preso é um órgão ligado à Secretaria da Administração Penitenciária do Estado de São Paulo cuja missão institucional é garantir trabalho, educação e cultura à população encarcerada nos presídios do Estado. 
Um deles (referindo-se a um dos presidiários) chegou a declarar: "Em toda minha vida de crime eu nunca senti emoção tão grande quanto a de trabalhar no teatro". Pois posso garantir, a ele e aos outros, que minha emoção não foi menor. Lembrado das palavras do Cristo, o problema do castigo de uma pessoa humana sempre me angustiou; e, mesmo impotente como seja, sempre foi profunda a compaixão que eu sinto por qualquer condenado. Assim, fiquei contente ao ver que minha peça tinha levado um pouco de alegria (e talvez alguns momentos de reflexão) tanto aos atores que a encenaram quanto ao público de detentos que assistiu ao espetáculo. Por alguns momentos voltei a ser o menino que, na pequena cidade de Tapera, sertão da Paraíba, por ordem da tia e da mãe ia, com outros irmãos, visitar os presos da cadeia local, numa tentativa (também inócua, sei) de amenizar sua terrível e dolorosa condição (Suassuna, 1999).

Diante da repercussão alcançada, o trabalho ganha continuidade, sob o título de Projeto Teatro nas Prisões. O espetáculo seguinte continuou a se aprofundar no universo farsesco e popular da dramaturgia de Suassuna, com a montagem de A Pena e a Lei, que iniciou suas apresentações em 2000, e seguiu o caminho trilhado pela montagem anterior: apresentaçōes dentro da própria unidade, apresentaçōes em outros presídios e apresentações em outros espaços, chegando inclusive a levar a encenação para outras cidades que não a Capital Paulista, como Sorocaba.

Desta vez, entretanto, o grupo conseguiu permissão para contar com a presença de uma atriz, o que representou uma enorme conquista para o processo, já que por se tratar de uma unidade masculina, haveria considerável alteração do material dramatúrgico, vez que os integrantes se negavam a viver papéis femininos.

A permissão, concedida pela unidade penal, para que uma jovem atriz fizesse parte dos ensaios, considerando obviamente que ela realizaria atividades que pressupunham contato fí- sico e estudo coletivo para a elaboração das cenas, tudo isso ganhava alto valor simbólico, visto que consolidava não só a credibilidade artística do grupo, como ampliava sua responsabilidade para com a própria manutenção do teatro como atividade dentro da unidade penal.

Neste sentido, é imprescindível atribuir ao teatro o caráter agregador e coletivo inerente a seu exercício. Daí o peso de suas conquistas em um presídio, instituição total que prima pela massificação no trato dos indivíduos a ele submetidos, promovendo o que Goffman define como mortificação do eu (Goffman, 2001).

A experiência do COC acaba quando o Complexo do Carandiru é desativado, e seus presos são transferidos, em sua maioria, para a Penitenciária do Tremembé, no final de 2001.

Mas durante todo aquele ano, o grupo constrói O Rei da Vela, de Oswald de Andrade, texto escrito em 1933, mas que só conheceria os palcos em uma montagem histórica realizada pelo Teatro Oficina em 1967, quando o contexto político do país renovaria os significados de um texto que, definitivamente, é um dos mais instigantes já produzidos pela nossa dramaturgia, e que conquista cada vez mais atualidade na medida em que as estruturas políticas, sociais e econômicas do Brasil parecem pouco ter mudado ao longo de todos esses anos que nos separam do autor modernista.

Esta montagem representou a conclusão de um longo processo de construção de sentidos para a possibilidade de inserção de práticas teatrais em presídios, ampliando justificativas que estivessem vinculadas simplesmente ao caráter "ressocializador" da arte. O discurso da ressocialização invariavelmente promoveria um julgamento das atitudes individuais de cada participante do processo, desviando a atuação da prática teatral de seu eixo mais interessante: $o$ de promover um exercício coletivo de construção artística, que se faz mais denso à medida em que se amplia a discussão estética e que promove melhores resultados quanto maior é o envolvimento dos integrantes em todas as camadas da criação cênica. 
O Rei da Vela foi convidado, pelo próprio diretor do Teatro Oficina, Zé Celso Martinez Corrêa, a se apresentar no emblemático edifício que serve de palco, há mais de trinta anos, para as históricas encenações de um grupo que é referência na trajetória das lutas de resistência cultural do teatro brasileiro frente aos problemas financeiros e estéticos que fazem parte da identidade de nossos grupos teatrais.

A apresentação obteve grande repercussão e garantiu quase o dobro da capacidade do teatro, com o público lotando os três andares do espaço que compóe a área que lhe é destinada, no arrojado teatro projetado pela arquiteta italiana Lina Bo Bardi. Lá o público presenciou, além do espetáculo, parte do trato dispensado aos apenados, e que os muros da prisão escondem: os atores, ainda recebendo aplausos calorosos da platéia, foram algemados com brutalidade e, escoltados por dois policiais cada um, saíram correndo em direção ao porta-malas do camburão que os levaria ao presídio.

Em 2002 e 2003, a construção de um novo espaço e de novos vínculos de reconhecimento artístico aconteceria na Penitenciária Feminina do Tatuapé (PFT), ao lado da famigerada unidade da Febem, famosa por promover, junto a seus 1.600 adolescentes detidos, as mais escandalosas rebeliōes do sistema da Fundação Estadual para o Bem - Estar do Menor.

Ali, durante dois anos, entre muitas lutas por um lugar para ensaios, o projeto só conseguiu finalmente ganhar um espaço próprio e apropriado para o trabalho em uma sala do segundo andar do pavilhão destinado às unidades de trabalho, em meados do segundo ano de processo.

Como isso foi conquistado? Pela boa vontade do presídio, infelizmente, não foi. A FUNAP decidiu, pela primeira vez na história da instituição, pagar uma bolsa-salário às participantes (este caráter de ineditismo acontece porque o que está em jogo é uma ação cultural e educativa, o que representou grande passo para a política educacional e cultural promovida pela FUNAP). Assim, o teatro foi alçado à categoria de "posto de trabalho", e não mais de "atividade cultural", o que elevou sensivelmente a credibilidade da atividade artística em relação aos apoios que vinha recebendo da direção e dos funcionários da unidade penal.

Nos meses de setembro e outubro, foram realizadas doze apresentações do espetáculo Mulheres de Papel, adaptação do texto Homens de Papel, de autoria de Plínio Marcos, cuja obra sempre esteve voltada para a exposição das mazelas sociais de nosso país e de suas personagens marginalizadas.

A cena, tomada por um grupo de catadoras de papel, decididas a promover uma greve contra os abusos que vinham sofrendo do comprador do material por elas recolhido do lixo, tem como conflito principal discussões na ordem dos limites entre as expectativas individuais e seu confronto com decisões de ordem coletiva, materializadas no embate entre o grupo e a personagem Nhanha, que não pretende aderir à paralisação pela necessidade de conseguir dinheiro para levar a filha ao médico.

Essa complexa relação entre decisões coletivas, por um lado, e opções individuais, por outro, acabava por refletir o processo de construção das regras que conduziam os ensaios e que, portanto, definiram o próprio processo de construção do grupo. Tratava-se de um relacionamento diferente do habitual, para as presas, com o conceito de regras, que até então não se apresentavam a elas como um corpo orgânico, passível de alterações em fluxo dinâmico a fim de atender às necessidades do grupo, e que só teriam sentido se realmente fossem obedecidas não por medo de punição, mas por serem essenciais ao pleno funcionamento dos ensaios.

O espetáculo foi visto por aproximadamente mil pessoas, entre presas e público "de fora”, composto por muitas pessoas que entravam em um presídio pela primeira vez, o que significava uma clara possibilidade de derrubada dos muitos muros que a sociedade erige em relação ao universo penal.

Entretanto, a despeito de toda a repercussão obtida pelo trabalho, o presídio decidiu 
interromper as apresentações para o público externo, alegando impossibilidade do setor disciplinar em revistar, com a devida qualidade, todas as pessoas que adentravam a unidade a cada apresentação. Em verdade, essa alegação é fruto do medo do corpo funcional do presídio diante da exposição de sua incompetência e de sua incapacidade de lidar com uma platéia diferenciada, formada por um público diverso, inconformada com os maus tratos a que era submetida pelos responsáveis pela revista na entrada da unidade prisional.

A conclusão recaiu de forma drástica sobre o próprio trabalho, com a decisão da FUNAP em retirar o projeto da Penitenciária Feminina do Tatuapé, o que representou um golpe muito duro para as participantes do processo. De qualquer forma, a decisão repercutiu em instâncias mais elevadas na hierarquia da Secretaria da Administração Penitenciária, que derrubou a diretoria responsável pela saída do projeto da unidade, o que não deixa de revelar a importância atribuída ao teatro por figuras importantes na implantação de políticas públicas destinadas à população encarcerada.

$\mathrm{O}$ que se seguiu foi a possibilidade, oferecida pela FUNAP, de realização do projeto Teatro nas Prisões em um outro contexto. Em março de 2004, o Núcleo Panóptico de Teatro é fundado junto à Cooperativa Paulista de Teatro, de forma a oficializar o vínculo de um grupo de atores profissionais que foram se reunindo a Jorge Spínola ao longo de toda sua experiência com teatro nas prisões. A esses artistas uniu-se um grupo de ex-presidiários e outro de presos em regime semi-aberto, totalizando vinte pessoas. Em dezembro daquele ano, o grupo realizou oito apresentações do espetáculo $\mathrm{Mu}$ ros no Pavilhão 2 do desativado (mas ainda vivo na memória do sistema penal paulista) Carandiru, e seguiu em temporada, com apresentações gratuitas em diversos espaços da capital paulistana, durante o ano de 2005.

O espetáculo tomou como pontos de partida o conto O Muro, de Jean-Paul Sartre e cenas de $O$ Balcão, de Jean Genet, que se uniram ao trabalho de criação dos atores e do encenador a fim de produzir um forte discurso cênico cujo objetivo central era o de manifestar o valor da resistência diante da opulência dos opressores e da necessidade de se construir um apelo contra as formas de tortura, seja as que se encontram mascaradas em gestos assistencialistas, seja nas suas formas escancaradas e humilhantes, como agressões físicas e manifestações de força injustas, tão comuns no trato com os indivíduos encarcerados.

Diante da possibilidade de realizar um processo teatral não mais submetido às regras das unidades prisionais, mas fora delas, e envolver homens e mulheres em regime semi-aberto e egressos do sistema penal, a construção do espetáculo conquistou a possibilidade de abordar determinadas questôes com um grau de complexidade que anteriormente precisava ficar subentendido, diante das limitações impostas pelos presídios.

O conto de Sartre, O Muro, trata do tema, tão caro ao existencialismo, da situação limite. Um grupo de revolucionários é torturado, das mais diversas formas, a fim de que se revele o paradeiro do líder do movimento. Transplantado para a nossa complexa realidade atual, quem seriam os revolucionários, quem seriam os torturadores?

Partindo dessas indagações e aprofundando debates e análises que se seguiam às improvisaçôes, que procuravam estabelecer a aquisição dos códigos e princípios da linguagem cênica e do trabalho de interpretação teatral, o grupo realizava instigante processo de elaboração de sentidos para as ações e diálogos do texto, que conquistavam novas possibilidades a cada vez que iam para a cena.

Passaram pelo processo aproximadamente cinqüenta pessoas, muitas das quais acabaram abandonando o trabalho à medida que conseguiam um emprego, ou simplesmente não se identificavam com a natureza da prática teatral. Com os presos em regime semi-aberto, a situação ficava bem mais complicada: suas vidas ainda estão submetidas à estrutura da prisão, e cada 
deslize por eles cometido, seja por chegarem atrasados à unidade prisional, seja por tentarem entrar na unidade carregando qualquer produto que lhes é proibido portar, como peças de roupa ou alimentos, acarreta o desligamento automático do trabalho.

São pequenos deslizes que a prisão transforma em grandes delitos, sobretudo porque um indivíduo em regime semi-aberto vive metade do tempo com a ilusão da liberdade, e briga por manter o máximo dela durante o tempo em que ainda ficará atrás das grades, provocando confusões por coisas que consideramos absolutamente banais, como o direito de levar uma revista para o quarto (no caso deles, para a cela).

De qualquer forma, o trabalho obteve repercussão graças ao fato de haver se transformado no último evento que possibilitaria ao público conhecer parte da antiga Casa de Detenção, o Carandiru, o mais famoso dos presídios, alçado a monumento da irresponsabilidade de nossos políticos para com o tratamento do preso, quando cenário do famoso massacre em que cento e onze homens foram assassinados pela tropa de choque da Polícia Militar, sob ordem do então governador Luiz Antonio Fleury Filho, no fim de 1992.

As oito apresentações tiveram lotação esgotada e o projeto, que recebeu o reconhecimento de instâncias públicas de financiamento, através da aprovação do trabalho do Núcleo Panóptico pela comissão da Lei de Fomento ao Teatro para a Cidade de São Paulo, Lei $13.279-02,{ }^{3}$ hoje alia às apresentações a continuidade de seu aperfeiçoamento e consolidação de sua pesquisa, iniciando uma nova investigação, desta vez dirigida pela integrante Lígia Borges e tendo como foco explorar a estrutura e as falas do texto Marat-Sade, de Peter Weiss.
A relação entre um processo de criação teatral investigativo e propiciador de reflexão em contextos prisionais ganha diversas possibilidades de sentido nos âmbitos pedagógico, artístico e social, no que tange às relações entre a cena e as possíveis repercussões de um processo criador, fundamentado em princípios da liberdade, em um regime punitivo baseado, justamente, na privação de liberdade.

Essa contradição, fundamental entre as muitas outras com as quais se lida ao promover um exercício de criação teatral em uma prisão, está intrincada no cerne de todas as atividades enquadradas nas propostas "reabilitadoras" promovidas pelo presídio. Embora a maior parte dos esforços da instituição penal esteja voltada para o controle da massa encarcerada e para o combate a manifestações que abalem sua ordem interna, o discurso defendido pela prisão é outro, o de que sua ação está voltada para a transformação do infrator em cidadão responsável, mediante cumprimento da pena.

Sobre esta questão, Foucault, no célebre Vigiar e Punir, erige elaborada explanação, demonstrando que, paralelamente à consolidação da prisão como modelo punitivo que se sobressaiu no mundo dito civilizado, organizaram-se uma série de saberes a partir de discursos produzidos pelas mais diversas ciências (a arquitetura, a psicologia, o direito, a psiquiatria, a pedagogia etc.). A soma desses discursos terminou elaborando a Criminologia, responsável fundamental para a construção do conceito moderno de delinqüência, que sobrepõe ao ato transgressor, portanto criminoso, o impulso transgressor, de tal forma que passa a se debruçar sobre o indivíduo, agora envolvido em uma série de laudos, exames e testes que vão ligá-lo eternamente à sua atitude penalizada.

3 A Lei de Fomento ao Teatro destina à produção teatral da cidade de São Paulo 6 milhões de reais, distribuídos em dois processos de seleção realizados no decorrer de cada ano. Os critérios de avaliação compreendem a análise da importância de se viabilizarem propostas cênicas que não pretendem se submeter a leis do mercado e que se preocupem em multiplicar e difundir a arte teatral por toda a cidade. 
Dessa forma, não resta ao indivíduo penalizado, objeto da ação de todo aparato técnico-científico elaborado pelo saber penitenciário, alternativa que não carregar eternamente o estigma de ter sido preso, e sua vida será tolhida de toda sorte de possibilidades oferecidas aos "normais", de tal forma que não restem muitas alternativas que não o retorno ao mundo do crime. É por essa razão que no Brasil os índices de reincidência penal chegam ao número alarmante de $70 \%$. Trata-se de um número assustador, sobretudo se levarmos em consideração que a grande maioria (65\%) cumpre pena por pequenos furtos e roubos. Não são os violentos assassinos que a mídia insiste em construir, não são os perigosos mentores do crime organizado a maior parte dos condenados.

A trajetória do projeto Teatro nas Prisões e do trabalho do diretor teatral Jorge Spínola, à frente do Núcleo Panóptico de Teatro, faz parte dessa história, que ainda permanece marginalizada e pouco debatida por instâncias mais amplas da sociedade.

Perdida entre discussões concernentes à promoção da reabilitação, portanto centradas em questões da própria promoção da ressocialização, e temas relacionados a uma proposta de integração entre arte teatral e processos educativos em prisões, a prática teatral em universos carcerários corre o risco de se perder na ingenuidade de propostas que não promovam o envolvimento crítico de seus participantes, con- cluindo com apresentações que sirvam apenas aos intuitos da instituição penal em se mostrar apoiadora de atividades culturais, ainda que de pouco valor artístico e educacional.

O projeto Teatro nas Prisóes e o Núcleo Panóptico de Teatro defenderam, inicialmente de forma sutil, a partir de textos que criticavam as estruturas que mantêm as desigualdades sociais de nosso país, e atualmente de forma mais escancarada, ao fazer uso de um texto que revela as estruturas de manutenção da ordem injusta que permanece embasando a política e a manutenção das mazelas nacionais, a possibilidade de realização de espetáculos que construam notável qualidade artística e envolvimento real de todos os participantes na produção de um discurso cênico que irradie questionamento e sentidos diversos aos que tiverem possibilidade de apreciá-lo.

Para além do próprio processo teatral, e de todos os problemas que envolvam a produção de uma encenação dentro de presídios, tendo na população carcerária seus principais protagonistas, interessa ao Núcleo Panóptico o momento do encontro com o público, quando este, normalmente surpreendido pelo poder transformador da arte, reage emocionado à quebra da expectativa de assistir a um espetáculo com presos, e conhece uma face que não costuma associar a esse universo: a beleza e o prazer da fruição de uma arte de resistência, que derruba preconceitos e constrói novas conotações a essas vidas encarceradas. 


\section{Referências bibliográficas}

COSTA, Maria Rita Freire. A Arte como Processo de Recriação em Presidios. Catálogo do Projeto. São Paulo, 1983.

ESCOBAR, Ruth. Dossiê de uma Rebelião. São Paulo: Global, 1982. Coleção Passado e Presente.

FERNANDES, Rofran. Teatro Ruth Escobar: 20 anos de resistência. São Paulo: Global, 1985.

FOUCALT, Michel. Vigiar e Punir - Nascimento da Prisão. Petrópolis: Vozes, 2004.

FREIRE, Paulo e BETTO, Frei. Essa Escola Chamada Vida - Depoimentos ao Repórter Ricardo Kotscho. São Paulo: Ática, 1986.

ILANUD. "Direitos Humanos em Cena: oficinas teatrais com a população prisional de São Paulo". Revista do ILANUD, n. 21. São Paulo, 2002.

GOFFMAN, Erving. Manicômios, Prisões e Conventos. São Paulo: Perspectiva, 2001.

MARCOS, Plínio. Homens de Papel e Barrela. São Paulo: Ed. Parma, 1976.

SUASSUNA, Ariano. "Valquíria e o Carandiru". Folha de S. Paulo, 13 jul. 1999. Caderno Ilustrada. 